Original Research Paper

\title{
Benthic and Substrate Category Profile of Coral Reef in Labuan Pandan Waters, East Lombok
}

\author{
Noar Muda Satyawan ${ }^{1 *} \&$ Novita Tri Artiningrum ${ }^{2}$ \\ ${ }^{1}$ Program Studi Perikanan Tangkap, Politeknik Kelautan dan Perikanan Jembrana, Bali, Indonesia \\ ${ }^{2}$ Program Studi Pemanfaatan Sumberdaya Perikanan Fakultas Perikanan Universitas 45 Mataram, Indonesia
}

\author{
Article History \\ Received : January $08^{\text {th }}, 2021$ \\ Revised : January $16^{\text {th }}, 2021$ \\ Accepted : January $21^{\text {th }}, 2021$ \\ Published : January $28^{\text {th }}, 2021$ \\ *Corresponding Author: \\ Noar Muda Satyawan, \\ Program Studi Perikanan \\ Tangkap, Politeknik Kelautan \\ dan Perikanan Jembrana, Bali, \\ Indonesia \\ Email: \\ satyawan.nm@gmail.com
}

\begin{abstract}
Coral reefs are unique ecosystems and only occur in the tropics area. One of the coral reef distribution in Indonesia is Lombok Island. The coral reefs in Lombok Island under degradation conditions caused by natural and human activities. The purpose of this study was to provide an overview of the benthic profile and substrate of coral reefs in the Labuhan Pandan waters, Eastern Lombok. Observations were conducted in March 2019 at 5 stations using the Underwater Photo Transect (UPT) method. The results showed that in general benthic coral reefs were dominated by Acropora Branching $(35.40 \%)$ then followed by Soft Coral (20.89\%), DCA (14.08\%), Coral Foliose (11.07\%), Rubble $(7.36 \%)$ and Halimeda $(2.77 \%)$. The highest percentage of Acropora Branching were found at KND_01 station (63.33\%) followed by PTG_01 (49.13\%), PTG_02 (31.18\%), BDR_01 (21.73\%), and PTG_03 (11.00\%). The highest DCA percentage was found at BDR_01 station $(29.27 \%)$ while Soft Coral was found dominant at PTG_02 (47.67\%). Halimeda was only found in PTG_02 (1.87\%) and PTG_03 (12.00\%). Differences in the composition of benthic and substrate may be caused by differences in water conditions at each station.
\end{abstract}

Keywords: Benthic category; Substrate; Coral reef; Labuhan Pandan; East Lombok

\section{Pendahuluan}

Terumbu karang (coral reefs) merupakan ekosistem yang khas dan hanya terdapat di daerah tropis. Tercatat sebanyak 600.000 spesies terumbu karang di dunia dan terpusat di kawasan IndoPasifik (Plaisance et al. (2011). Terumbu karang adalah ekosistem yang sangat penting dan memberikan dampak ekonomi secara langsung kepada masyarakat pesisir. Selain itu, Ekosistem terumbu karang juga berperan dalam menyediakan habitat bagi berbagai macam organisme laut seperti Echinodermata, Crustacea, Polychaeta, Chordata, Moluska, Annelida dan biota laut yang hidup bebas seperti plakton dan ikan (Satyawan et al., 2013; Satyawan et al., 2014; Satyawan \& Artiningrum, 2019).

Terumbu karang merupakan ekosistem yang sangat rapuh dan pada umumnya ditemukan di perairan dangkal dengan kondisi perairan yang iernih dan hanoat Rucaknva terumhu karano danat This article is licensed under a Creative Commons Attribution 4.0 International License. menurunkan produktivitas perikanan yaitu mempengaruhi sistem reproduksi, komposisi komunitas dan kemampuan dalam penyebarannya (Grimsditch dan Rodney, 2006). Berdasarkan hasil survey kondisi terumbu karang yang dilakukan oleh P2O-LIPI, dari 1.067 titik pengamatan di seluruh Indonesia 36,18\% termasuk dalam kategori jelek, 34,30\% kategori sedang, 22,96 kategori baik dan 6,56\% kategori sangat baik (Hadi et al., 2018).

Salah satu daerah penyebaran terumbu karang di Indonesia adalah di Pulau Lombok yaitu di pesisir dan pulau-pulau kecil (gili). Secara umum kondisi terumbu karang di Pulau Lombok mengalami degradasi, Subhan (2016) melaporkan bahwa tutupan substrat terumbu karang di Pulau Lombok didominasi oleh karang mati beralga $42,62 \%$, sedangkan tutupan karang keras hanya sebesar 29,52\%. Lokasi dengan tutupan karang tertinggi adalah di Kabupaten Lombok Barat sebesar 35,52\% dan terendah ditemukan di 
Satyawan, NM \& Artiningrum, NT (2021). Jurnal Biologi Tropis, 21 (1): 171 - 178 DOI: http://dx.doi.org/10.29303/jbt.v21i1.2448

Kabupaten Lombok Utara sebesar 22,78\%. Sedangkan di Kabupaten Lombok Timur khususnya Gili Sulat - Lawang tutupan karang berkisar antara $27,8 \%$ - 49,58\%. Bahtiar dkk. (2017) melaporkan bahwa tutupan karang di perairan Teluk Sekotong berada pada kondisi jelek - sedang.

Ekosistem terumbu karang di kawasan Kabupaten Lombok Timur, selain menghadapi tekanan dari aktivitas penangkapan ikan yang tidak ramah lingkungan serta aktivitas pariwisata yang tinggi juga harus menghadapi ancaman kerusakan secara alami seperti gempa bumi, gelombang, badai dan pemanasan global. Perubahan kondisi perairan dapat memicu perubahan pada kondisi ekosistem terumbu karang. Kondisi ekosistem terumbu karang dapat diketahui dari komposisi bentik penyusunnya. Oleh karena itu penelitian ini bertujuan untuk memberikan gambaran profil bentik dan substrat terumbu karang sebagai dasar pengelolaan ekosistem terumbu karang yang berkelanjutan di perairan Labuhan Pandan Lombok Timur.

\section{Bahan dan Metode}

\section{Waktu dan Lokasi Penelitian}

Pemantauan kondisi ekosistem terumbu karang dilakukan pada bulan Maret 2019 di Gili Bidara, Gili Kondo dan Gili Petagan yang merupakan wilayah administrasi Desa Labuhan Pandan Kecamatan Sambelia, Lombok Timur, Provinsi Nusa Tenggara Barat. Lokasi ini cukup dekat dengan episentrum gempa sehingga menyebabkan kerusakan pada hampir 95\% bangunan masyarakat setempat. Pengamatan dilakukan pada 5 stasiun yaitu stasiun Gili Bidara (BDR_01), Gili Kondo (KND_01), Gili Petagan 1 (PTG_01), Gili Petagan 2 (PTG_02), dan Gili Petagan 3 (PTG_03).

Tabel 1. Kode masing-masing kategori bentik terumbu karang (biota dan substrat)

\begin{tabular}{|c|c|c|c|c|c|}
\hline Kode & Kategori & Kode & Kategori & Kode & Kategori \\
\hline & Coral & & Recent Dead Coral & & Sponge \\
\hline $\mathrm{ACB}$ & Acropora Branching & DC & Recently Dead Coral & SP & Sponge \\
\hline $\mathrm{ACD}$ & Acropora Digitate & & Dead Coral with Algae & & Fleshy Seaweed \\
\hline ACE & Acropora Encrusting & DCA & Dead Coral with algae & AA & Algal assemblage \\
\hline ACS & Acropora Submassive & TA & Turf Algae & MA & Makro Algae \\
\hline ACT & Acropora Tabulate & & Soft Coral & & Other Biota \\
\hline $\mathrm{CB}$ & Coral Branching & $\mathrm{SC}$ & Soft Coral & $\mathrm{CA}$ & Coralline algae \\
\hline $\mathrm{CE}$ & Coral Encrusting & & Rubble & HA & Halimeda \\
\hline $\mathrm{CF}$ & Coral Foliose & $\mathrm{R}$ & Rubble & OT & Other(Fauna) \\
\hline CHL & Coral Heliopora & & Sand & $\mathrm{ZO}$ & Zoanthid \\
\hline $\mathrm{CM}$ & Coral Massive & S & Sand & & Tape, wand, shadow \\
\hline CME & Coral Millepora & & Silt & TWS & Tape, Wand, Shadow \\
\hline CMR & Coral Mushroom & SI & Silt & & \\
\hline $\mathrm{CS}$ & Coral Submassive & & Rock & & \\
\hline CTU & Coral Tubipora & RK & Rock & & \\
\hline
\end{tabular}


Satyawan, NM \& Artiningrum, NT (2021). Jurnal Biologi Tropis, 21 (1): 171 - 178

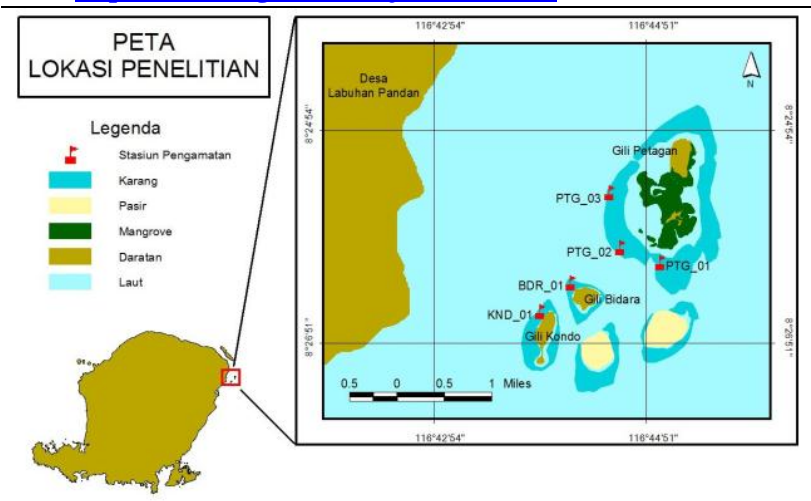

Gambar 1. Peta Lokasi Penelitian

\section{Pengambilan Data Terumbu Karang}

Variabel yang diukur dalam penilaian kesehatan ekosistem terumbu karang adalah persentase tutupan karang hidup. Data persentase tutupan karang diambil dengan menggunakan metode UPT (Underwater Photo Transect) (Giyanto et al., 2010; Giyanto, 2012a; Giyanto, 2012b). Pengambilan data dengan metode UPT ini dilakukan dengan penyelaman SCUBA dan mengambil gambar tutupan terumbu karang di dalam kuadrat menggunakan kamera bawah air. Pengambilan gambar dilakukan pada transek yang dibuat di kedalaman 5-7 meter.

Di setiap stasiun penelitian dipasang transek permanen sepanjang 50 meter. Transek permanen tersebut berupa tali tangsi (tasik) sepanjang 50 meter. Setiap 10 meter dipasang patok besi diameter $16 \mathrm{~mm}$ dan sebuah pelampung kecil, sebagai penanda tambahan. Pada titik nol dipasang dua pasak dan dua pelampung kecil sebagai penanda awal transek. Pelampung kecil tersebut mengapung di dalam air, sekitar $40 \mathrm{~cm}$ dari substrat dasar terumbu, sehingga hanya kelihatan oleh penyelam.

Pengambilan gambar dilakukan pada kuadrat yang diletakkan di setiap satu meter sepanjang transek, sehingga pada setiap transek setidaknya ada 50 gambar. Pemotretan pada meter ke-1 (frame 1), meter ke-3 (frame 3) dan frameframe nomor ganjil berikutnya dilakukan di sebelah kanan garis transek, sedangkan untuk frame-frame nomor genap (frame 2, frame 4, dan seterusnya) dilakukan di sebelah kiri garis transek. Pemotretan kuadrat dilakukan pada jarak sekitar $60 \mathrm{~cm}$ dari dasar substrat sehingga luas bidang setiap frame pemotretan sekitar $2552 \mathrm{~cm}^{2}$. Untuk mempermudah konsistensi jarak pemotretan digunakan bantuan kuadrat ukuran $58 \times 44 \mathrm{~cm} 2$ terbuat dari besi diameter $6 \mathrm{~mm}$. Kuadrat dicat dengan warna cerah agar mudah dikenali di dalam air.

\section{Pengolahan Data Terumbu Karang}

Gambar kuadrat hasil pemotretan dianalisis menggunakan piranti lunak (software) CPCe (Kohler \& Gill 2006). Sebanyak 30 titik sampel terpilih secara acak untuk setiap frame gambar. Setiap titik sampel tersebut diidentifikasi dan diberi kode sesuai kategori biota dan substrat (Tabel 1). Persentase tutupan masing-masing kategori biota dan substrat untuk setiap frame gambar dihitung menggunakan rumus:

Persen tutupan kategori $=\frac{\text { Jumlah titik kategori tersebut }}{\text { banyaknya titik acak }} \times 100$

\section{Hasil dan Pembahasan}

\section{Ketegori Bentik dan Substrat Terumbu Karang}

Profil kategori bentik dan substrat karang di perairan Labuhan Pandan, Kabupaten Lombok Timur disajikan pada Gambar 2. Secara umum, profil bentik dan substrat karang didominasi oleh Acropora Branching (ACB) dengan persentase tutupan $35,40 \%$ kemudian diikuti oleh Soft Coral (SC) 20,89\%, Dead Coral with Algae (DCA) $14,08 \%$, Coral Foliose $(11,07 \%)$, Rubble (R) 7,36\%, dan Halimeda (HA) 2,77\%. English et.al. (1994) menerangkan bahwa jenis karang yang dominan disuatu habitat tergantung pada kondisi lingkungan atau habitat tempat karang tersebut hidup. Karang Acropora sp., umumnya merupakan salah satu kelompok karang yang sangat dominan pada suatu perairan (Thamrin, 2006).

Fluktuasi kondisi lingkungan akan mempengaruhi tingkat pertumbuhan, bentuk pertumbuhan, kemampuan reproduksi karang (Kleypas et al. 1999), yang akhirnya memberikan pengaruh pada kelimpahan, komposisi dan keanekaragaman komunitas karang (Baker et al. 2008). Nontji (1987), menambahkan pertumbuhan karang juga akan lebih baik didaerah berarus atau bergelombang dibandingkan dengan perairan yang tenang. Karang bercabang dan karang batu atau masif lebih menyukai daerah yang bersubstrat keras dan yang berarus dikarenakan adanya sirkulasi unsur hara yang cukup berlimpah (Panggabean \& Setiadji 2011). 
Karang bercabang jenis Acropora dan non Acropora dibedakan berdasarkan keberadaan aksial koralit. Karang Acropora memiliki aksial dan radial koralit sedangkan karang non Acropora tidak memiliki aksial koralit (Suharsono 2010). Dari berbagai jenis lifeform karang, jenis karang bercabang merupakan jenis yang diketahui cenderung sensitif terhadap perubahan suhu lingkungan sehingga perubahan suhu di atas kondisi normal atau rata-rata dapat segera diketahui (Rani 2001).

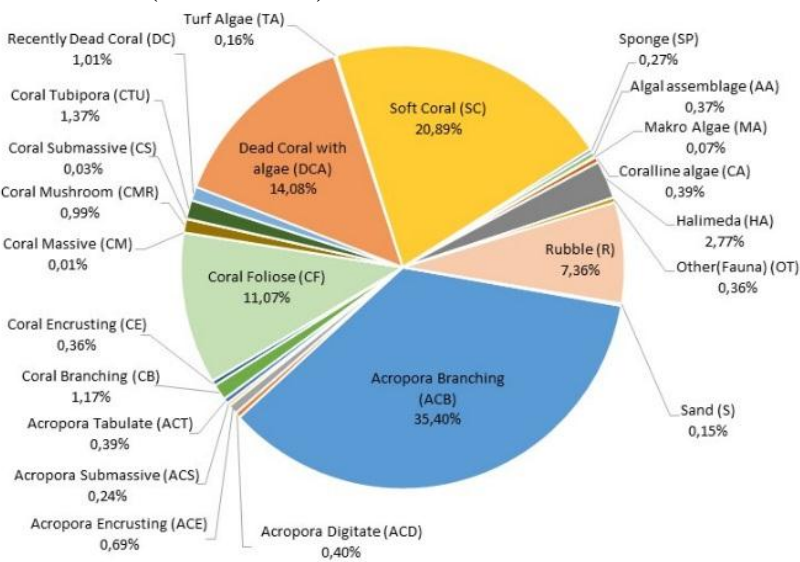

Gambar 2. Profil kategori bentik dan substrat karang di perairan Labuhan Pandan, Lombok Timur

\section{Tutupan Kategori Bentik dan Substrat Karang}

Perbandingan persentase tutupan kategori bentik dan substrat karang pada masing-masing stasiun pengamatan ditunjukkan pada Gambar 3. Acropora Branching ditemukan dominan pada beberapa stasiun. Tutupan Acropora Branching tertinggi ditemukan pada stasiun Gili Kondo (KND_01) sebesar 63,33\% kemudian diikuti oleh Gili Petagan 1 (PTG_01) 49,13\%, Gili Petagan 2 (PTG_02) 31,18\%, Gili Bidara (BDR_01) 21,73\% dan Gili Petagan 3 (PTG_03) 11,00\%.

Soft coral (SC) ditemukan dengan persentase tutupan tertinggi di stasiun Gili Petagan 2 (PTG_02) 47,67\%, Gili Petagan 3 (PTG_03) 21,80\%, Gili Bidara (BDR_01) 16,13\%, Gili Petagan 1 (PTG_01) $14,20 \%$, dan Gili Kondo (KND_01) 4,67\%. Keberadaan karang lunak (soft coral) dapat merupakan indikator kondisi karang keras (hard coral). Pertumbuhan jenis karang lunak mengalami blooming apabila kondisi karang keras sudah dalam keadaan kritis atau rusak (Panggabean \& Setiadji 2011). Panggabean \& Setiadji (2011) menambahkan bahwa karang lunak merupakan kelompok karang yang relatif mudah tumbuh dalam waktu singkat dibandingkan dengan karang batu. Gerakan air yang disebabkan oleh arus menyebabkan karang lunak mampu bertahan dan melekat pada substrat yang keras dan mendukung proses pertumbuhannya.

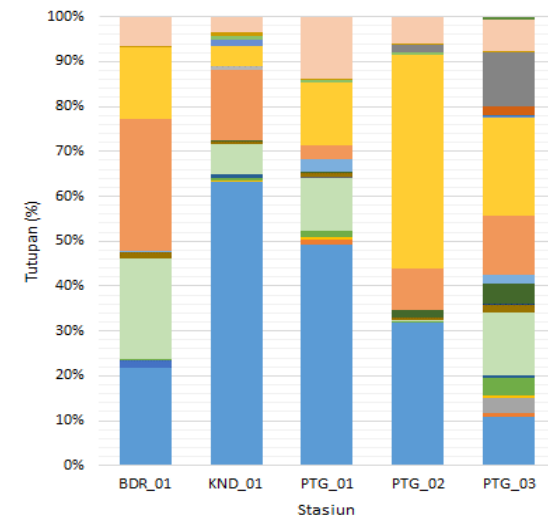

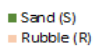

$$
\begin{aligned}
& \text { n- Other(Fauna) (OT) } \\
& \text { - Halimeda (HA) } \\
& \text { - Coralline agae (CA) } \\
& \text { - Makr o Agae(MA) } \\
& \text { Algal arsembiage (AA) } \\
& \text { - Sponge (SP) } \\
& \begin{array}{l}
\text {-Soft Coral (SC) } \\
\text { Turf Agae (TA) }
\end{array} \\
& \text { Dead Coral with algae (DCA) } \\
& \text { - Recently Dead Coral (DC) } \\
& \text { - Coral Tubipora (CTU) }
\end{aligned}
$$

Gambar 3. Perbandingan persentase tutupan kategori bentik dan substrat karang pada masing-masing stasiun pengamatan

Manuputty (1990) menyatakan bahwa senyawa terpen terutama pada marga Sinularia, Lobophytum dan Xenia mempunyai pengaruh alleopatik terhadap biota sesil di sekitarnya sehingga dapat menghambat pertumbuhan dan mematikan biota sesil yang ada di sekitarnya. Evans et al. (2011) menambahkan bahwa karang lunak dan kipas laut dianggap sebagai biota pengganggu karang. Kehadiran mereka mampu mendominasi ekosistem terumbu karang dan diketahui memproduksi toksin yang menyebabkan kematian karang yang letaknya berdekatan, kemudian akan menempati daerah tersebut. Selain hal tersebut, ketersediaan substrat yang minim akibat dominasi karang lunak menyebabkan anakan karang susah untuk berkembang. Hal ini tentu saja mengganggu proses pemulihan ekosistem terumbu karang.

Persentase tutupan Dead Coral with Algae (DCA) tertinggi ditemukan pada stasiun Gili Bidara (BDR_01) sebesar 29,27\%, kemudian diikuti oleh Gili Kondo (KND_01) 15,67\%, Gili Petagan 3 (PTG_03) 13,33\%, Gili Petagan 2 (PTG_02) 9,20\%, dan Gili Petagan 1 (PTG_01) 2,93\%. Birkeland (1997) menjelaskan bahwa kematian karang dapat disebabkan oleh aspek fisik dan kimiawi, pada aspek fisik kematian atau kerusakan terumbu karang terjadi karena terkena 
Satyawan, NM \& Artiningrum, NT (2021). Jurnal Biologi Tropis, 21 (1): 171 - 178 DOI: http://dx.doi.org/10.29303/jbt.v21i1.2448

hantaman gelombang besar yang dapat memporak porandakan terumbu karang, sedangkan dari aspek kimiawi adalah adanya polutan dari aktivitas manusia didarat yang menyebabkan eutrofikasi, sedimentasi, polusi serta masuknya air tawar yang berlebihan dari darat karena terjadinya erosi melalui proses run-off. Muttaqin et al. (2014) menambahkan bahwa kematian karang telah memberikan ruang untuk tumbuhnya alga sebagai kompetitor terumbu karang.

Coral Foliose (CF) ditemukan dengan tutupan tertinggi pada stasiun Gili Bidara (BDR_01) sebesar 22,40\%, kemudian diikuti oleh Gili Petagan 3 (PTG_03) 14,13\%, Gili Petagan 1 (PTG_01) 11,93\%, Gili Kondo (KND_01) 6,67\%, dan Gili Petagan 2 (PTG_02) 0,20\%. Bentuk pertumbuhan karang batu (massive), melebar (encrusting), dan lembaran (foliose) merupakan suatu cara bagi karang tersebut untuk mentoleransi kondisi kecepatan arus permukaan yang dapat menyebabkan perairan yang keruh agar dapat menyerap sinar matahari untuk kegiatan fotosintesis Zooxanthelae yang melekat di atas karang tersebut (Panggabean \& Setiadji 2011). Supriharyono (2007) menambahkan bahwa karang yang tumbuh atau teradaptasi pada perairan yang sedimennya tinggi cenderung berbentuk Folliose.

Secara umum tutupan pecahan karang/Rubble di perairan Labuhan Pandan tergolong kecil yaitu 7,36\%. Rubble (R) tertinggi ditemukan pada stasiun Gili Petagan 1 (PTG_01) sebesar 13,87\%, kemudian diikuti oleh Gili Petagan 3 (PTG_03) 6,80\%, Gili Bidara (BDR_01) 6,67\%, Gili Petagan 2 (PTG_02) 6,00\% dan Gili Kondo (KND_01) 3,47\%. Persentase tutupan rubble menggambarkan besarnya kerusakan ekosistem terumbu karang dalam suatu perairan. Ancaman kerusakan terumbu karang berasal dari alam dan akibat dari aktifitas manusia. Wilkinson (2004) menjelaskan bahwa kerusakan alami biasanya disebabkan oleh gelombang, badai, tsunami dan naiknya temperatur air laut akibat perubahan iklim. Ancaman yang berasal dari akifitas manusia adalah sedimentasi, eutrofikasi, metode penangkapan ikan yang tidak ramah lingkungan (menggunakan bom atau racun), pembangunan jembatan dan pelabuhan, pembuangan limbah dan pariwisata (Ress et al. 1999; Raymundo et al. 2007; Munoz-Chagin 1997; Willoughby et al. 1997; Burke et al. 2002). Brown (2004) menambahkan bahwa lokasi menyelam populer akan mengundang masuknya para wisatawan yang apabila tidak terkontrol bisa merusak ekosistem terumbu karang.
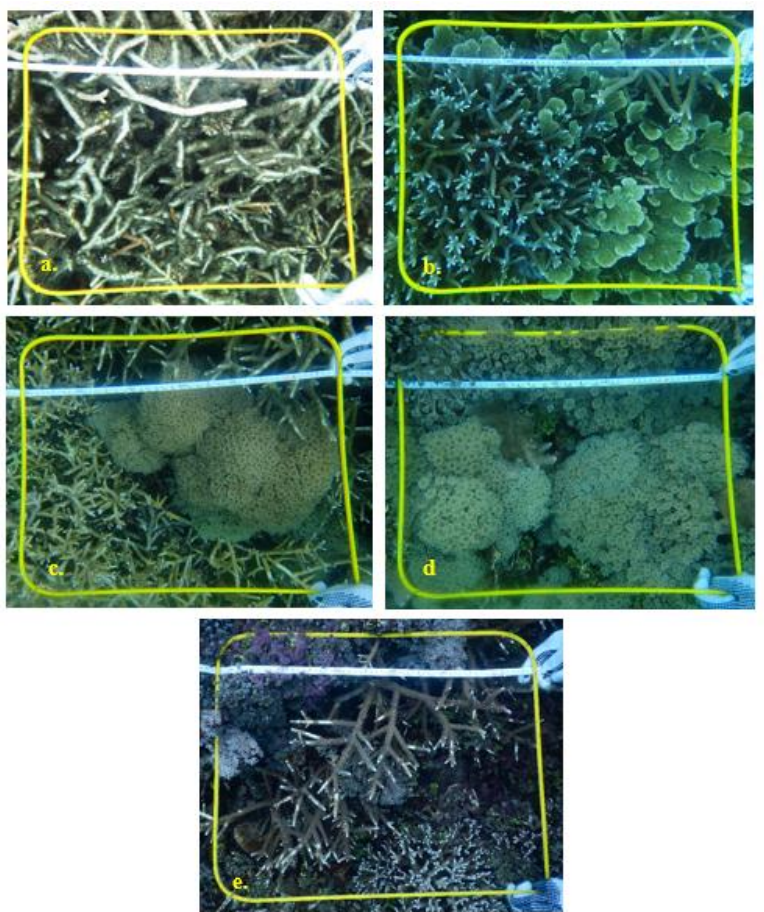

Gambar 4. Kondisi terumbu karang di perairan Labuhan Pandan, Lombok Timur (a. Gili Bidara (BDR 01); b. Gili Kondo (KND_01); c. Gili Petagan 1 (PTG_01); d. Gili Petagan 2 (PTG_02); e. Gili Petagan 3 (PTG_03))

Tutupan makroalga Halimeda (HA) ditemukan pada 2 stasiun pengamatan yaitu Gili Petagan 2 (PTG_02) 1,87\% dan Gili Petagan 3 (PTG_03) 12,00\%. Hal ini Hal ini mengindikasikan terjadinya kerusakan karang pada lokasi tersebut yang ditandai dengan munculnya Halimeda atau yang dikenal sebagai biota pioner (Siringoringo, $d k k$. 2012). Stasiun ini merupakan lokasi pengamatan yang memiliki arus yang cukup kuat sehingga banyak ditemukan karang yang patah/roboh. Ayhuan et al. (2017) melaporkan bahwa semakin kuat arus maka pertubuhan makroalga akan semakin cepat yang disebabkan oleh meningkatnya difusi nutrien di dalam sel sehingga secara otomatis akan mempercepat metabolisme. Alga merupakan kompetitor terumbu karang dalam hal perebutan ruang atau cahaya (McCook dan Diaz-Pulido, 2001). Faktor utama yang berpengruh terhadap pertumbuhan makroalga adalah keberadaan hewan herbivora (pemakan alga) dan ketersediaan nutrien 
Satyawan, NM \& Artiningrum, NT (2021). Jurnal Biologi Tropis, 21 (1): 171 - 178

DOI: http://dx.doi.org/10.29303/jbt.v21i1.2448

yang secara tidak langsung berpengaruh pada komunitas terumbu karang (Fabricius, 2011).

Keberadaan terumbu dalam ekosistem perairan menjadi penopang kehidupan biota laut ekonomis, seperti ikan udang dan biota bentik lainnya. Rusaknya terumbu karang dapat menurunkan produktivitas perikanan yaitu mempengaruhi baik dalam reproduksi, komposisi komunitas dan kemampuan dalam penyebarannya (Grimsditch dan Rodney, 2006). Kerusakan yang diakibatkan oleh polusi dan overfishing benarbenar telah mengancam keutuhan dan eksistensi dari terumbu karang, di samping itu, dampak dari pemanasan global juga yang secara tidak langsung di akibatkan oleh aktivitas manusia sangat berpengaruh besar terhadap keselamatan terumbu karang (Campbell and Reece, 2010). Oleh karena itu, aktivitas manusia di darat dan perairan sebaiknya dikelola secara terpadu dengan pengelolaan ekosistem terumbu karang agar dapat memanfaaatkan sumberdaya hayati laut secara berkesinambungan.

\section{Kesimpulan}

Berdasarkan hasil pengamatan dan pembahasan maka dapat ditarik kesimpulan bahwa profil bentik dan substrat terumbu karang di perairan labuhan Pandan Lombok Timur secara umum didominasi oleh Acropora Branching $(35,40 \%)$ kemudian diikuti oleh Soft Coral (20,89\%), DCA (14,08\%), Coral Foliose (11,07\%), Rubble (7,36\%) dan Halimeda (2,77\%). Persentase Acropora Branching tertinggi ditemukan pada stasiun KND_01 $(63,33 \%)$ diikuti oleh PTG_01 (49,13\%), PTG_02 (31,18\%), BDR_01 (21,73\%), dan PTG_03 (11,00\%). Persentase DCA tertinggi ditemukan di stasiun BDR_01 (29,27\%) sedangkan Soft Coral ditemukan dominan pada PTG_02 (47,67\%). Halimeda hanya ditemukan pada PTG_02 $(1,87 \%)$ dan PTG_03 (12,00\%). Perbedaan komposisi bentik dan substrat kemungkinan disebabkan oleh perbedaan kondisi perairan pada masing-masing stasiun.

\section{Ucapan Terima Kasih}

Ucapan terimakasih kami sampaikan kepada DRPM Kemenristek Dikti atas pendanaan yang diberikan sehingga penelitian ini dapat terlaksana dan diselesaikan tepat pada waktunya.
Terimakasih juga kami sampaikan kepada LPPM Universitas 45 Mataram dan P3M Politeknik Kelautan dan Perikanan Jembrana. Tidak lupa kami sampaikan terimakasih kepada pihak-pihak yang membantu dalam pengambilan data sampai dipublikasikannya hasil penelitian ini.

\section{Referensi}

Ayhuan, H.V., N.P. Zamani, \& D. Soedharma. (2017). Analisis struktur komunitas makroalga ekonomis penting di perairan intertidal Manokwari, Papua Barat. Jurnal Teknologi Perikanan dan Kelautan, 8 (1): 19-38. https://doi.org/10.24319/jtpk.8.19$\underline{38}$

Bachtiar I, Karnan, Santoso D, Japa L, Satyawan N., Atmanegara FK, \& Iien H. (2017). Monitoring Kesehatan Terumbu Karang dan Ekosistem Terkait di Sekotong, Lombok Barat. COREMAP-CTI. Jakarta: Lembaga Ilmu Pengetahuan Indonesia. Pp. 63

Baker, A.C., Glynn, P.W., \& Riegl, B., (2008). Climate change and coral reef bleaching: an ecological assessment of long-term impacts, recovery trends and future outlook. Estuarine, Coastal and Shelf Science 80: 435-471.

https://doi.org/10.1016/j.ecss.2008.09.003.

Birkeland, C. (1997). Life and Death of coral reefs. Chapman \& Hall. New York.

Brown, R., Gruber, J.G., Hardesty, J., Meyer, M., Roth, M., Thompson J. \& Weir, W. (2004). Reef Relief the Coral Reef Theacher Guide. Captain Roland Roberts House Environmental Center. AbacosBahamas.Pp175.

Burke L, Selig, E., \& Spalding, M., (2002). Reefs at Risk in Southeast Asia. World Resources Institute (WRI), Washington DC, USA.

Campbell, N.A. \& Reece, J.B. (2010). Biologi, Edisi Kedelapan Jilid 3 Terjemahan: Damaring Tyas Wulandari. Jakarta: Erlangga. 
Satyawan, NM \& Artiningrum, NT (2021). Jurnal Biologi Tropis, 21 (1): 171 - 178

DOI: http://dx.doi.org/10.29303/jbt.v21i1.2448

English. S.C. Wilkinson \& Baker, V. (1994). Survey Manual for Tropical marine Resources. Australian of Marine Science. Townsville.

Evans, A. J., M. D. Steer, \& Belle, E. M. S. (2011). The Alcynocea (Soft Corals and Sea Fans) of Antsiranana Bay, Northern Madagaskar. Madagaskar Conservation and Development. 6: 29-36. https://doi.org/10.4314/mcd.v6i1.68062.

Fabricius, K.E. (2011). Factors determining the resilience of coral reefs to eutrophication: A review and conceptual model, in: Dubinsky, Z., N. Stambler (Eds.), Coral reefs: An ecosystem in transition. Springer Netherlands, Dordrecht.

Giyanto (2012a) Kajian tentang panjang transek dan jarak antar pemotretan pada penggunaan metode transek foto bawah air. Oseanologi dan Limnologi di Indonesia, 38 (1): $1-18$. http://oseanografi.lipi.go.id/dokumen/os x Xxviii_1_2013-5.pdf

Giyanto (2012b) Penilaian kondisi terumbu karang dengan metode transek foto bawah air. Oseanologi dan Limnologi di Indonesia $\begin{array}{lll}\text { Vol. } & 38 & \text { (3):377-389. }\end{array}$ http://oseanografi.lipi.go.id/dokumen/os x xxviii 1 2013-5.pdf

Giyanto, Iskandar B.H., Soedharma D., \& Suharsono (2010). Effisiensi dan akurasi pada proses analisis foto bawah air untuk menilai kondisi terumbu karang. Oseanologi dan Limnologi di Indonesia, 36 (1): $111-130$

http://lipi.go.id/publikasi/efisiensi-danakurasi-pada-proses-analisis-foto-bawahair-untuk-menilai-kondisi-terumbukarang/2461.

Grimsditch, G.D. \& Rodney V.S. (2006). Coral Reef Resilience and Resistance to Bleaching. IUCN Resilience Science Group Working Paper Series - No.1. Switzerland: The International Union for the Conservation of Nature (IUCN)
Hadi, T.A., Giyanto, Prayudha, B., Hafitz, M., Budiyanto, A., Suharsono. (2018). Status Terumbu Karang indonesia 2018. Coremap-CTI. Jakarta: Lembaga Ilmu Pengetahuan Indonesia. Pp26. http://oseanografi.lipi.go.id/haspen/buku\% 20status\%20karang\%202018\%20digital.pd f.

Kleypas, J.A., McManus, J.W., \& Meñez, L.A.B., (1999). Environmental limits to coral reef development: where do we draw the line? American Zoologist 39, 146-159. https://doi.org/10.1093/icb/39.1.146.

Kohler, K.E. \& S.M. Gill, (2006). Coral Point Count with Excel extensions (CPCe): A Visual Basic program for the determination of coral and substrate coverage using random point count methodology. Computers and Geosciences, 32 (9): 12591269. https://doi.org/10.1016/j.cageo.2005.11.00 $\underline{9}$

Manuputty, A. E. W. 1990. Senyawa Terpen Dalam Karang Lunak (Octocorallia: Alcyonace). Oseana, 15 (2): $77-84$. http://www.oseanografi.lipi.go.id/dokumen loseana_xv(2)77-84.pdf

McCook, L.J., \& Diaz-Pulido, G. (2001). Competition between corals and algal turfs along a gradient of terrestrial influence in the nearshore central great barrier reef. Coral Reefs, 19: 419-425. https://link.springer.com/article/10.1007/s0 $\underline{03380000119}$

Munoz-Chagin R.F. (1997). Coral transplantation program in the Paraiso coral reef, Cozumel Island, Mexico. Proceedings of the $8^{\prime}$ International Coral Reef Symposium 2: 2075-2078.

http://www.reefbase.org/resource_center/p ublication/pub 9983.aspx

Muttaqin, M., Kamal, M.M., Haryadi, S., Pardede, S.,Tarigan, S. \& Campbell, S. (2014). Dampak Pemutihan karang terhadap ekosistem terumbu karang pada tahun 2010 di Perairan Utara Aceh. J. Ilmu dan 
Satyawan, NM \& Artiningrum, NT (2021). Jurnal Biologi Tropis, 21 (1): 171 - 178

Teknologi Kelautan Tropis, 1 (5):15-21. https://journal.ipb.ac.id/index.php/jtpk/artic le/download/10042/11635

Nontji, A. (1987). Laut Nusantara. Jakarta: Djambatan

Panggabean, A.S., Setaidji, B. (2011). Bentuk pertumbuhan Karang Daerah Tertutup Dan Terbuka Di Perairan Sekitarpulau Pamegaran, Teluk Jakarta. Bawal, 3 (4): 255-260.

https://www.researchgate.net/publication/3 13844557

Plaisance, L., Caley, M.J., Brainard, R.E \& Knowlton, N. (2011). The diversity of coral reefs: What are we missing? Plos One. 6 (10): $\quad 1 \quad-7$ https://doi.org/10.1371/journal.pone.00250 $\underline{26}$

Rani, C. (2001). Pemutihan Karang: Pengaruhnya Terhadap Karang. Hayati 8 (3) : 86-90. http://lib.pdii.lipi.go.id/index.php?p=show detail\&id $=71292 \&$ keywords $=$

Raymundo L.J, Maypa, A.P., Gomez, E.D., \& Cadiz, P. (2007). Can dynamite-blasted reefs recover? a novel, low-tech approach to stimulating natural recovery in fish and coral populations. Marine Pollution Bulletin Vol. 54:

1009-1019. https://doi.org/10.1016/j.marpolbul.2007.0 $\underline{2.006}$

Satyawan, N.M., Tutupoho, S., Wardiatno. Y. \& Tsuchiya, M. (2013). Feeding behaviour and bioerosion: the ecological role of the rock-boring urchin, Echinometra mathaei (de Blainville, 1825), in Okinawa reef flat. Aquatic Science \& Management, 1 (1): 10 16.

https://doi.org/10.35800/jasm.1.1.2013.197 6

Satyawan, N.M., Wardiatno, Y. \& Kurnia, R. (2014). Keanekaragaman Spesies dan Zonasi Habitat Echinodermata di Perairan Pantai Semerang, Lombok Timur. Jurnal Biologi Tropis, 14 (2): 83 - 92. http://dx.doi.org/10.29303/jbt.v13i1.66.
Satyawan, N.M. \& Atriningrum, N.T. (2019). Kondisi Eksisting Fauna Megabenthos di Perairan Labuhan Pandan Lombok Timur Pasca Gempa Bumi Lombok 7.0 Skala Richter Jurnal Biologi Tropis, 19 (2): 172 179.

http://jurnalfkip.unram.ac.id/index.php/JBT /article/download/1303/1028

Siringoringo, R.M., Palupi, R.D., \& Hadi, T.A. (2012). Biodiversitas Karang Batu (Scleractinia) di Perairan Kendari. Ilmu Kelautan, $\quad 17 \quad$ (1): $\quad 23-30$. https://www.researchgate.net/profile/Tri_H adi4/publication/318648548.

Suharsono (2010). Jenis-jenis karang di Indonesia. Coremap Program. Jakarta (ID): LIPI Pres.

Supriharyono (2007). Pengelolaan Ekosistem Terumbu Karang. Jakarta: Djambatan.

Thamrin (2006). Karang: Biologi Reproduksi dan Ekologi. Pekanbaru: Minamandiri Press.

Wilkinson C.R. (2004). Status of coral reefs of the world: 2004. Global Coral Reef Monitoring Network GCRMN, Australian Institute of Marine Science, Townsville, Queensland, Australia. $\quad 557 \quad$ pp. https://www.iucn.org/content/status-coralreefs-world-2004

Willoughby N.G, Sangkoyo, H. \& Lakaserus, B.O. (1997). Beach Litter: an increasing and changing problem for Indonesia. Marine Pollution Bulletin, 34: 469-478. https://doi.org/10.1016/S0025326X(96)00141-5. 